\title{
A Study of Encapsulation Resin Containing Hexagonal Boron Nitride (hBN) as Inorganic Filler
}

\author{
Tzu Hsuan Chiang, ${ }^{1}$ and T.-E. Hsieh ${ }^{1,2}$
}

ERRATUM TO: JOURNAL OF INORGANIC

AND ORGANOMETALLIC POLYMERS AND

MATERIALS DOI: 10.1007/s10904-006-9037-8

The submitted and accepted dates for this paper were inadvertently omitted. The dates are as follows:

Submitted August 23, 2005; accepted November 22, 2005

The online version of the original article can be found at: http:// dx.doi.org/10.1007/s10904-006-9037-8

${ }^{1}$ Department of Materials Science and Engineering, National Chiao Tung University, 1001 Ta-Hsueh Road, Hsinchu, 30050, Taiwan ROC.

2 To whom correspondence should be addressed.

E-mail: tehsieh@cc.nctu.edu.tw 